\title{
INDENTIFIKASI FAKTOR RISIKO HUMAN ERRORS DALAM PENERAPAN MANAJEMEN SUMBER DAYA MANUSIA DI PERUSAHAAN JASA KONSTRUKSI
}

\author{
Muhammad Khilbran ${ }^{1}$, Wahyu Indra Sakti ${ }^{2}$ \\ ${ }^{1}$ Mahasiswa Magister Teknik Sipil Universitas Tarumanagara \\ Email:rezi_munizar@yahoo.com \\ ${ }^{2}$ Dosen Magister Teknik Sipil Universitas Tarumanagara \\ Email:wahyusaidi@gmail.com
}

\begin{abstract}
ABSTRAK
Penyebab utama kecelakaan kerja dalam proyek konstruksi adalah yang terkait dengan karakteristik proyek konstruksi yang unik, lokasi kerja yang berbeda, cuaca terbuka dan cuaca, waktu pelaksanaan yang terbatas, keamanan fisik tinggi yang dinamis dan menuntut, dan banyak penggunaan tenaga kerja tidak terampil. Ditambah dengan manajemen keselamatan yang sangat lemah, akibatnya pekerja bekerja dengan metode implementasi konstruksi berisiko tinggi. Penelitian ini merupakan faktor human error dalam proyek infrastruktur jembatan Paya Dapur - Kp. Tinggi di Kabupaten Aceh Selatan. Data dikumpulkan melalui angket survei responden dari pelaku konstruksi yang terlibat dalam proyek di jembatan Paya Dapur - Kp. Tinggi di Kabupaten Aceh Selatan, Provinsi Aceh. Hasil penelitian menunjukkan bahwa ada 10 faktor kesalahan manusia, termasuk peran dan tanggung jawab konsultan pengawas dan konsultan perencana belum maksimal, kegagalan untuk menggunakan alat pelindung diri / keselamatan diri dengan benar, prosedur kerja yang buruk, prosedur operasi standar yang buruk (Standard Operation Procedure /SOP), penerangan yang buruk, standar kerja sering fleksibel, tidak ada pemeriksaan awal, desain peralatan pengguna yang tidak sesuai atau tidak kompatibel, tingkat kebisingan yang berlebihan dan tata letak fasilitas kerja yang buruk.
\end{abstract}

Kata Kunci: Kesalahan Manusia; Faktor Kesalahan Manusia; Jembatan; Aktor Konstruksi; Kabupaten Aceh Selatan

\section{ABSTRACT}

The main causes of work accidents in construction projects are those related to unique construction project characteristics, different working locations, weather-exposed and weathered, limited implementation time, dynamic and demanding high physical security, and many uses unskilled labor. Coupled with a very weak safety management, consequently the workers work with high-risk construction implementation methods. This research analyzes the human error factor in the bridge infrastructure project of Paya Dapur - Kp. High in the District of South Aceh. The data was collected through a questionnaire survey of respondents from construction actors involved in the project at Paya Dapur - Kp bridge. High in Aceh Selatan District, Aceh Province. The results showed that there were 10 human error factors, including the roles and responsibilities of the supervisor consultant and the planner consultant not yet maximal, the failure to use self-protective equipment / self-safety correctly, poor working procedures, poor Standard Operation Procedure (SOP), poor lighting, work standards often flexed, no initial checks, inappropriate or incompatible user equipment designs, excessive noise levels and poor layout of work facility layouts.

Keywords: Human Error; Human Error Factor; Bridges; Construction Actors; South Aceh District

\section{PENDAHULUAN}

\section{Latar Belakang}

Proyek konstruksi merupakan sekumpulan aktivitas yang saling berhubungan dimana ada titik awal dan titik akhir serta hasil tertentu, proyek biasanya bersifat lintas fungsi sumber daya 
manusia sehingga membutuhkan bermacam keahlian (skills) dari berbagai profesi dan organisasi. Setiap proyek adalah unik, bahkan tidak ada dua proyek yang persis sama, ditambah lagi dengan beragamnya budaya kerja di setiap daerah dan sifat manusia pada proyek.

Perkembangan dunia konstruksi di provinsi Aceh menjadi persaingan ketat di dalam perusahaan jasa konstruksi antara perusahaan satu dengan perusahaan lainnya. Ketatnya persaingan ini membuat perusahaan jasa konstruksi harus dapat memaksimalkan potensi dan kemampuan masing-masing perusahaan terutama dalam pengelolaan sumber daya perusahaan diantaranya keuangan, manusia, teknologi, material, budaya, dan sistem manajemen.

Proses pembangunan di Indonesia sendiri belum menunjukkan keseimbangan antara kemajuan program pembangunan dengan peningkatan kesadaran kecelakaan kerja. Hal ini dapat dibuktikan dengan banyaknya kecelakaan kerja yang terjadi. Di provinsi Aceh juga terjadi beberapa kecelakaan kerja, salah satunya ialah jatuhnya pekerja lift di pusat perbelanjaan di kota Banda Aceh, runtuh dinding parit dan lain-lain.

Berbagai penyebab utama kecelakaan kerja pada proyek konstruksi adalah hal-hal yang berhubungan dengan karakteristik proyek konstruksi yang bersifat unik, lokasi kerja yang berbeda-beda, terbuka dan dipengaruhi cuaca, waktu pelaksanaan yang terbatas, dinamis dan menuntut ketahanan fisik yang tinggi, serta banyak menggunakan tenaga kerja yang tidak terlatih. Ditambah dengan manajemen keselamatan kerja yang sangat lemah, akibatnya para pekerja bekerja dengan metode pelaksanaan konstruksi yang berisiko tinggi.

Penelitian ini menganalisis manusia pada sebuah proyek konstruksi untuk human error dilakukan oleh para pelaku jasa konstruksi di Kabupaten Aceh Selatan.

\section{Rumusan Masalah}

Berdasarkan latar belakang di atas, maka pokok permasalahan dalam penelitian ini adalah apa saja faktor-faktor human error factors yang mempengaruhi penerapan manajemen sumber daya manusia di perusahaan jasa konstruksi?

\section{Tujuan Penelitian}

Berdasarkan rumusan masalah di atas, maka tujuan dari penelitian ini adalah untuk mengetahui menentukan human error factors yang mempengaruhi penerapan manajemen sumber daya manusia di perusahaan jasa konstruksi

\section{Batasan Penelitian}

Batasan penelitian bertujuan untuk membatasi pembahasan pada pokok penelitian, sehingga penelitian ini terbatas pada:

a. Objek penelitian yang ditinjau hanya pada Kabupaten Aceh Selatan, Provinsi Aceh

b. Penelitian terbatas pada proyek jembatan Paya Dapur - Kp. Tinggi di Kabupaten Aceh Selatan.

\section{Manfaat Penelitian}

Manfaat yang ingin dicapai atau diperoleh dari penelitian ini antara lain adalah sebagai berikut:

a. Manfaat teoritis, penelitian ini dapat memberikan informasi mengenai strategi antisipasi dalam memperkecil human error yang mungkin dihadapi oleh perusahaan kontruksi dalam pelaksanaan pembangunan infrastruktur di Provinsi Aceh 
b. Manfaat praktis, penelitian ini diharapkan bisa menjadi gambaran untuk menghadapi dan mengantisipasi human error yang mungkin dihadapi oleh perusahaan jasa konstruksi, serta menjadi gambaran mengenai hal-hal apa saja yang harus diperhatikan dan diperbaiki dari pelaksanaan kegiatan manajemen sumber daya manusia.

c. Manfaat bagi kontraktor dan penyelenggara proyek konstruksi, penelitian ini diharapkan dapat menjadi dasar masukkan yang berguna sebagai bahan pertimbangan masalah human error pada proyek khususnya dalam penyediaan pemahaman perlindungan diri bagi sumber daya manusia dan mengetahui sejauh mana tingkat kesadaran pekerja akan pentingnya pemahaman human error.

d. Manfaat bagi pekerja konstruksi, penelitian ini diharapkan mampu menjawab kebutuhan pekerja konstruksi dalam hal pemenuhan peralatan perlindungan diri, pemahaman mengenai human error pada proyek yang sesuai dengan kondisi fisik para pekerja di Indonesia dan di provinsi Aceh.

e. Manfaat bagi pemerintah, penelitian ini diharapkan dapat menjadi bahan pertimbangan bagi pemerintah dalam rangka mempersiapkan prosedur perlindungan kerja yang baru

\section{TINJAUAN PUSTAKA}

\section{Industri Konstruksi}

Dalam undang-undang istilah industri konstruksi sering disebut sebagai jasa konstruksi. Industri konstruksi adalah suatu kegiatan di sektor ekonomi yang melakukan transformasi berupa perencanaan, desain, keuangan dan procurement, pembangunan, pengoperaian dan pemeliharaan dari beberapa sumber daya untuk menghasilkan fasilitas dan perasaran ekonomi dan sosial (Siti, 1999).

\section{Peran Pelaku Jasa Konstruksi}

Menurut Ervianto (2005), orang atau badan yang membiayai, merencanakan dan melaksanakan bangunan tersebut disebut unsur- unsur pelaksanaan proyek konstruksi. Unsur-unsur pelaksana pembangunan yang terlibat dalam kegiatan pembangunan adalah owner, konsultan perencana (struktur dan arsitek), kontraktor, dan konsultan pengawas.

\section{Manajemen Sumber Daya Manusia}

Menurut Effendi (2007), sumber daya manusia adalah perencanaan, pengorganisasian, pengarahan dan pengawasan kegiatan-kegiatan pengadaan pengembangan, pengintegrasian, pemeliharaan, dan pelepasan sumber daya manusia agar mencapai tujuan organisasi dan masyarakat. Tujuan dari manajemen sumber daya manusia secara umum adalah untuk memastikan bahwa organisasi mampu mencapai keberhasilan melalui kerja sama dan kontribusi aktif dari manusia.

\section{Manajemen Risiko}

Risiko adalah ancaman terhadap kehidupan, properti atau keuntungan finansial akibat bahaya yang terjadi (Duffield \&Trigunarsyah, 1999). Secara umum risiko dikaitkan dengan kemungkinan (probabilitas) terjadinya peristiwa diluar yang diharapkan. Jadi risiko adalah variasi dalam hal-hal yang mungkin terjadi secara alami atau kemungkinan terjadinya peristiwa diluar yang diharapkan yang merupakan ancaman terhadap properti dan keuntungan finansial akibat bahaya yang terjadi. 


\section{Teori Perilaku Kecelakaan Kerja (Accident Behavior)}

Menurut Reason (1990), teori perilaku mendefinisikan bahwa suatu kegiatan atau tindakan ditampilkan seseorang dari hubungannya dengan orang lain dan sekitarnya, atau tindakan seseorang dalam rangka adaptasi dengan sekelilingnya baik lingkungan maupun orang lain.

Perilaku dipicu dan dipengaruhi oleh berbagai faktor, yang disebut faktor penentu (determinant factors). Faktor penentu tersebut dapat diklasifikasikan ke 2 kelompok, yaitu:

a. Faktor dari dalam atau faktor internal yang umum disebut sebagai faktor bawaan (genetik). Faktor internal adalah faktor yang berkaitan dengan diri pribadi. Seperti kebutuhan (need), motivasi (motivation), kepribadian (personality), harapan (expectancy), pengetahuan (knowledge), persepsi (perception), dan masih banyak lagi faktor internal lainnya.

b. Faktor lingkungan adalah faktor yang berasal dari luar diri seseorang atau dari lingkungan, baik dengan manusia maupun sekelilingnya. Seperti: kelompok, masyarakat, atasan, orang tua, kawan dan lain-lain

\section{Human Error}

Human Error adalah kesalahan yang diakibatkan oleh kinerja kegiatan yang tidak boleh dilakukan sehingga dapat mengakibatkan kekacauan atau gangguan pada operasional atau menyebabkan kerusakan pada peralatan dan perlengkapan. Dhillon (1987) Human Error sering terjadi dalam kehidupan manusia saat melakukan aktivitasnya masing - masing, bahkan sering juga manusia disebut pembuat kesalahan. Menurut Sutalaksana (1979) hal ini terjadi karena keterbatasan manusia, baik hasil ciptaan (karya) ataupun perilaku manusia itu sendiri yang sangat sulit untuk mencapai kesempurnaan. Menurut Atkinson (1998), sebab-sebab human error dapat dibagi menjadi beberapa bagian, yaitu:

\section{a. Sebab-sebab primer}

Sebab-sebab primer merupakan sebab-sebab human error pada level individu. Untuk menghindari kesalahan pada level ini, ahli teknologi cenderung menganjurkan pengukuran yang berhubungan ke individu, misalnya meningkatkan pelatihan, pendidikan, dan pemilihan personil dalam Atkinson (1998). Bagaimanapun, saran tersebut tidak dapat mengatasi kesalahan yang disebabkan oleh penipuan dan kelalaian.

b. Sebab-sebab manajerial

Penekanan peran dari pelaku individual dalam kesalahan merupakan suatu hal yang tidak tepat. Kesalahan merupakan sesuatu yang tidak dapat dihindarkan, pelatihan dan pendidikan mempunyai efek yang terbatas dan penipuan atau kelalaian akan selalu terjadi, tidak ada satu pun penekanan penggunaan teknologi yang benar akan mencegah terjadinya kesalahan. Fakta ini telah diakui telah diakui secara luas pada literatur kesalahan dalam industri yang beresiko, dikutip dari Atkinson (1998). Karena itu merupakan peranan manajemen untuk memastikan bahwa pekerja melakukan pekerjaan dengan semestinya, untuk memastikan bahwa sumber daya tersedia pada saat dibutuhkan dan untuk mengalokasikan tanggungjawab secara akurat diantara pekerja yang terlibat.

c. Sebab-sebab global

Kesalahan yang berada di luar kontrol manajemen, meliputi tekanan keuangan, tekanan waktu, tekanan sosial dan budaya organisasi. 
Love and Josephson (2004) mendefinisikan kesalahan dan kelalaian sebagai "penyimpangan dari konstruksi yang tepat (meliputi pengecekan dan pengawasan) inspeksi teknis, dan instruksi yang memadai untuk pemeliharaan dan operasional bangunan.". Kesalahan yang terjadi dalam bangunan dapat berupa kesalahan manajemen, kesalahan teknis, maupun kesalahan karena lingkungan. Menurut Eldukair and Ayyub (1991), kesalahan manajemen meliputi kesalahan dalam tanggungjawab kerja, komunikasi kerja, dan kerja sama kerja. Sedangkan kesalahan lingkungan meliputi tekanan politik, tekanan keuangan, dan kondisi cuaca. Penyebab kesalahan yang berkaitan dengan human error adalah tingkah laku manusia.

Karena itu dapat dipastikan bahwa sebuah kesalahan meliputi elemen dari suatu yang patut dicela dari individu. Menurut Reason (1990), ada tiga macam kesalahan, yaitu skill based errors, rule based errors, dan knowledge based errors biasanya terjadi apabila seseorang melakukan pekerjaan yang rutin dan bukan merupakan suatu aktivitas yang membutuhkan pemikiran serta dikerjakan dalam kondisi yang familiar. Kebiasaan-kebiasaan yang dilakukan secara rutin termasuk dalam kondisi ini, dan biasanya kebiasaan-kebiasaan tersebut bila mengalami interupsi atau gangguan maka seringkali terjadi kesalahan.

Untuk menganalisa kecelakaan kerja yang terjadi dalam kegiatan konstruksi yang disebabkan human error dibutuhkan suatu pendekatan. Dalam hal ini ada dua macam pendekatan tersebut, yaitu:

\section{a. Person Approach}

Dalam pendekatan person approach ini seseorang dilihat sebagai seseorang yang mempunyai kehendak bebas untuk memilih melakukan tindakan yang aman atau tidak. Apabila sesuatu telah terjadi (kecelakaan atau hal-hal negatif lainnya), maka seseorang atau sekelompok inilah yang harus bertanggung jawab. Kelemahan lainnya dari pendekatan ini adalah melihat bahwa asal dari kesalahan itu adalah manusia. Dengan demikian itu akan mengisolasi tindakan yang tidak aman itu terhadap sistem yang ada.

\section{b. System Approach}

Dasar pemikiran yang dipakai dalam pendekatan ini adalah setiap orang dapat bersalah, sehingga setiap tindakan yang tidak diharapkan seperti kesalahan (error) dan pelanggaran (violation) dapat terjadi dimana saja.

\section{METODE PENELITIAN}

\section{Desain Penelitian}

Desain penelitian merupakan suatu cetak biru (blue print) bagaimana data dikumpulkan, diukur, dan dianalisis. Melalui desain, dapat dikaji alokasi sumber daya yang dibutuhkan (Umar, 2004).Penelitian ini dilakukan berdasarkan prosedur yang dikemukakan oleh Arikunto (2006), yaitu sebagai berikut:

a. Penelitian dimulai dengan pemilihan masalah.

b. Melakukan studi pendahuluan dengan maksud untuk mencari informasi yang diperlukan oleh peneliti agar masalah menjadi jelas kedudukannya.

c. Merumuskan masalah agar penelitian dapat dilaksanakan sebaik-baiknya, serta jelas harus memulai dari mana.

d. Merumuskan anggapan dasar atau sesuatu yang diyakini kebenarannya oleh peneliti yang akan berfungsi sebagai acuan penelitian.

e. Menentukan hipotesis atau kebenaran sementara yang ditentukan oleh peneliti, tetapi masih harus dibuktikan kebenarannya. 
f. Memilih pendekatan serta menentukan tipe penelitian yang akan digunakan.

g. Menentukan variabel dan sumber data penelitian.

h. Menentukan dan menyusun instrumen penelitian.

i. Mengumpulkan data menggunakan instrumen penelitian yang sudah ditentukan.

j. Menganalisis data yang sudah dikumpulkan.

k. Menarik kesimpulan berdasarkan hasil analisis data.

1. Menyusun laporan.

\section{Lokasi dan Sampel Penelitian}

Penelitian ini dilakukan di Kabupaten Aceh Selatan, yang berjarak dari Ibukota Provinsi berkisar 430 kilometer. Populasi pada penelitian ini adalah terbagi ke dalam kelompok responden praktisi dan responden pakar (expert). Responden praktisi adalah pelaku-pelaku konstruksi yang terlibat dalam proyek Jembatan ini, yang meliputi unsur pemberi tugas (owner), konsultan perencana (struktur dan arsitek). kontraktor pelaksana, konsultan pengawas, sedangkan responden pakar adalah akademisi dalam bidang manajemen sumber daya manusia dan manajemen konstruksi Responden dalam penelitian ini adalah pemberi tugas (owner) diambil 15 responden dari stafnya. Konsultan perencana berjumlah 15 responden, kontraktor pelaksana berjumlah 15 orang dan konsultan pengawas berjumlah 15 orang, sehingga jumlah responden dalam penelitian ini adalah 60 responden.

\section{Teknik Pengumpulan Data}

Pengumpulan data primer dilakukan dengan cara survei kuesioner, sedangkan data sekunder diperoleh dari dokumen-dokumen yang berkaitan dengan objek penelitian. Pengumpulan data sekunder didapatkan dari kontraktor pelaksana proyek yang diteliti, yang berupa gambar, daftar personalia dan kontrak kerja.

\section{Variabel Penelitian}

Variabel penelitian adalah faktor-faktor dari penelitian yang berkaitan terhadap fokus penelitian yang akan diteliti. Variabel penelitian diperoleh dari studi literatur studi pustaka dan yang sudah divalidasi oleh pakar, dapat dilihat pada tabel1 di bawah ini: 
Tabel 1. Variabel Penelitian

\begin{tabular}{|c|c|c|c|c|}
\hline No. & $\begin{array}{c}\text { Faktor } \\
\text { Penelitian }\end{array}$ & & Variabel Penelitian & Sumber \\
\hline \multirow[t]{15}{*}{1} & \multirow{15}{*}{$\begin{array}{c}\text { Induced } \\
\text { Human } \\
\text { Error } \\
\text { System }\end{array}$} & $\mathrm{X} 1$ & Manajemen hanya menerapkan komunikasi satu arah & Peter (2006) \\
\hline & & $\mathrm{X} 2$ & Kurangnya koordinasi dan tanggung jawab & Peter (2006) \\
\hline & & $\mathrm{X} 3$ & Lemahnya respons bila terjadi kecelakaan kerja & Peter (2006) \\
\hline & & $\mathrm{X} 4$ & Estimasi yang terlalu rendah dalam desain dan konstruksi & Eldukair and Ayyub (1991) \\
\hline & & $\mathrm{X} 5$ & Situasi yang benar-benar tidak diketahui & Eldukair and Ayyub (1991) \\
\hline & & $\mathrm{X} 6$ & Pelatihan dan pengawasan yang kurang memadai & Peter (2006) \\
\hline & & $\mathrm{X} 7$ & Prosedur kerja yang buruk & Peter (2006) \\
\hline & & $\mathrm{X} 8$ & Standard Operating Procedures (SOP) yang buruk & Peter (2006) \\
\hline & & X9 & Pemahaman yang salah pada saat keadaan darurat & Reason (1990) \\
\hline & & $\mathrm{X} 10$ & Tidak melakukan pemeriksaan awal & Reason (1990) \\
\hline & & $\mathrm{X} 11$ & Standar kerja sering diremehkan & Reason (1990) \\
\hline & & $\mathrm{X} 12$ & Komunikasi atas dan bawah yang sering terlambat/tertunda & Weighmann and Shappel (2006) \\
\hline & & $\mathrm{X} 13$ & Kedisiplinan dalam menjalankan SOP kurang & Kementrian PU (2018) \\
\hline & & $\mathrm{X} 14$ & Pemilihan metode konstruksi tidak memperhitungkan aspek risiko & Kementrian PU (2018) \\
\hline & & $\mathrm{X} 15$ & Tenaga kerja belum memiliki sertifikat kompetensi & Kementrian PU (2018) \\
\hline \multirow[t]{20}{*}{2} & \multirow{20}{*}{$\begin{array}{c}\text { Induced } \\
\text { Human } \\
\text { Error } \\
\text { Design }\end{array}$} & $\mathrm{X} 16$ & Kepercayaan/ketergantungan pada pihak lain & Eldukair and Ayyub (1991) \\
\hline & & $\mathrm{X} 17$ & Desain peralatan yang tidak sesuai atau tidak cocok dengan pengguna & Peter (2006) \\
\hline & & $\mathrm{X} 18$ & Kondisi lingkungan kerja dan tata letak peralatan yang buruk & Peter (2006) \\
\hline & & $\mathrm{X} 19$ & Prosedur kerja tidak jelas & Peter (2006) \\
\hline & & $\mathrm{X} 20$ & Peralatan kerja tidak layak & Peter (2006) \\
\hline & & $\mathrm{X} 21$ & Kompleksitas pekerjaan dan kondisi yang berlebihan & Peter (2006) \\
\hline & & $\mathrm{X} 22$ & Pencahayaan kurang baik & Peter (2006) \\
\hline & & $\mathrm{X} 23$ & Tingkat kebisingan berlebihan & Peter (2006) \\
\hline & & $\mathrm{X} 24$ & Rancangan tata letak fasilitas kerja yang buruk & Peter (2006) \\
\hline & & $\mathrm{X} 25$ & Menjalankan alat/perlengkapan tanpa ada wewenang & Peter (2006) \\
\hline & & $\mathrm{X} 26$ & Kegagalan menggunakan alat pelindung/keselamatan diri dengan benar & Peter (2006) \\
\hline & & $\mathrm{X} 27$ & Safety Factor pada pelaksanaan yang masih rendah & Kementrian PU (2018) \\
\hline & & $\mathrm{X} 28$ & $\begin{array}{l}\text { Peran dan tanggung jawab konsultan pengawas dan konsultan } \\
\text { perencana belum maksimal }\end{array}$ & Kementrian PU (2018) \\
\hline & & $\mathrm{X} 29$ & Sering tidak ikut aturan pada saat training & Reason (1990) \\
\hline & & $\mathrm{X} 30$ & Sering diluar kontrol pekerja di lapangan & Reason (1990) \\
\hline & & $\mathrm{X} 31$ & Sering tidak mengikuti briefing harian / Safety Talk / toolbox meeting & Reason (1990) \\
\hline & & $\mathrm{X} 32$ & Kesalahan pemahaman kesadaran kerja & Reason (1990) \\
\hline & & X33 & Tidak memperdulikan sign/tanda perhatian & Reason (1990) \\
\hline & & X34 & Sering menghilangkan beberapa langkah dalam sebuah prosedur & Weighmann and Shappel (2006) \\
\hline & & X35 & Sering menghilangkan beberapa langkah dalam sebuah checklist & Weighmann and Shappel (2006) \\
\hline \multirow[t]{21}{*}{3} & \multirow{21}{*}{$\begin{array}{c}\text { Pure } \\
\text { Human } \\
\text { Error }\end{array}$} & X36 & Pengetahuan yang tidak memadai & (Eldukair and Ayyub, 1991) \\
\hline & & $\mathrm{X} 37$ & Kurangnya pendidikan dan pelatihan & (Eldukair and Ayyub, 1991) \\
\hline & & $\mathrm{X} 38$ & Ketidaktahuan, kelalaian dan kecerobohan & (Eldukair and Ayyub, 1991) \\
\hline & & X39 & Kurangnya kemampuan untuk berkomunikasi & (Eldukair and Ayyub, 1991) \\
\hline & & $\mathrm{X} 40$ & Kurangnya imajinasi/tinjauan ke masa depan & (Eldukair and Ayyub, 1991) \\
\hline & & $\mathrm{X} 41$ & Kurangnya wibawa dalam mengambil keputusan & (Eldukair and Ayyub, 1991) \\
\hline & & $\mathrm{X} 42$ & Tingkat keterampilan dan kompetensi tenaga ahli yang rendah & (Peter,2006) \\
\hline & & $\mathrm{X} 43$ & Pekerja mengalami kelelahan dan tidak konsentrasi saat bekerja & (Peter,2006) \\
\hline & & $\mathrm{X} 44$ & Pekerja mengalami stress, mempunyai masalah pribadi & (Peter,2006) \\
\hline & & $\mathrm{X} 45$ & Pekerja menderita sakit atau masalah medis lainnya & (Peter,2006) \\
\hline & & $\mathrm{X} 46$ & Tidak mengenali karakteristik area kerja & Weighmann and Shappel (2006) \\
\hline & & $\mathrm{X} 47$ & Tidak fokus pada pekerjaan & Weighmann and Shappel (2006) \\
\hline & & $\mathrm{X} 48$ & Tidak punya pengalaman ketika kerja & Weighmann and Shappel (2006) \\
\hline & & $\mathrm{X} 49$ & Tidak cocok dengan kelompok kerja & Weighmann and Shappel (2006) \\
\hline & & $\mathrm{X} 50$ & Teknik kerja yang buruk & Weighmann and Shappel (2006) \\
\hline & & $\mathrm{X} 51$ & Cenderung terburu-buru mengerjakan sesuatu & Weighmann and Shappel (2006) \\
\hline & & $\mathrm{X} 52$ & Penekanan berlebihan pada pekerja & Weighmann and Shappel (2006) \\
\hline & & $\mathrm{X} 53$ & Terlalu percaya diri pada suatu pekerjaan & Reason (1990) \\
\hline & & $\mathrm{X} 54$ & Ego pribadi terlalu tinggi & Reason (1990) \\
\hline & & $\mathrm{X} 55$ & Menggunakan APD seadanya (tidak lengkap) & Reason (1990) \\
\hline & & $\mathrm{X} 56$ & Remunerasi tenaga ahli dan tenaga pengawas belum maksimal & Kementrian PU (2018) \\
\hline
\end{tabular}




\section{Metode Analisis Data}

Analisis data secara statistik dilakukan dengan menggunakan bantuan program komputer pengolah angka dan data statistik. Simulasi dilakukan setelah feedback kuesioner diolah kedalam bentuk angka, kemudian dilanjutkan dengan pengolahan menggunakan program komputer. Adapun tahapan-tahapan yang dilakukan dapat dilihat pada gambar 1 berikut ini:

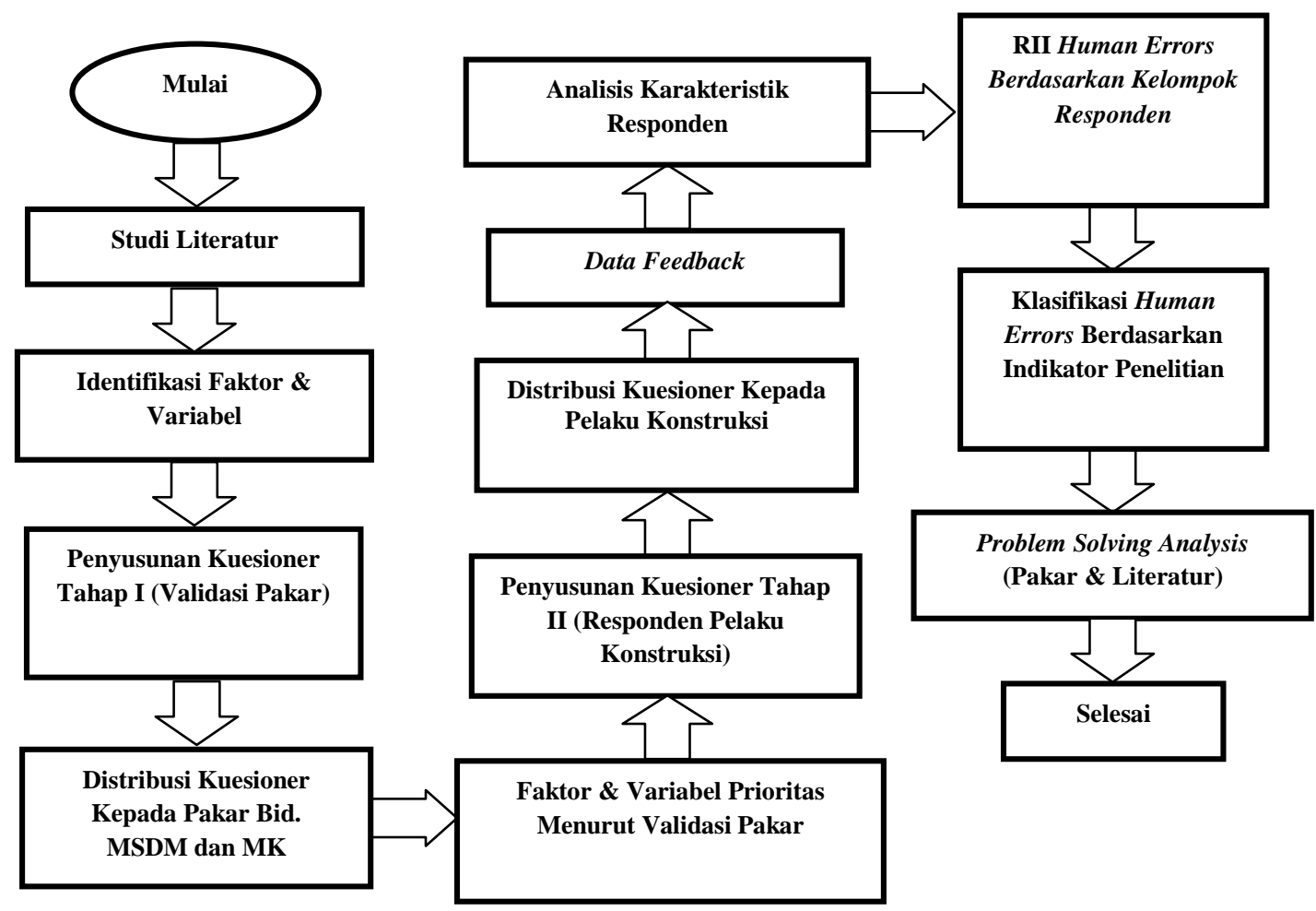

Gambar 1. Metode Analisis Data

\section{Analisis Relative Importance Index (RII)}

Analisis Relative Importance Index (RII) adalah suatu terminologi yang pertama kali dipublikasikan oleh Meyer, Barnett, dan Brown (1997). RII adalah suatu analisis yang memungkinkan suatu kuantitatif relatif, di mana semakin tinggi peringkat (rating) semakin tinggi pula pengaruh yang diberikan oleh variabel yang dimiliki (Hardjomuldjadi, 2009). Rumus yang digunakan adalah:

$$
\mathrm{RII}=\frac{\sum \mathrm{W}}{\mathrm{AxN}}
$$

Keterangan:

RII = Relative Importance Index

$\mathrm{W}=$ Bobot yang diberikan untuk faktor penyebab dominan (1,2,3,4 dan 5)

A $=$ Bobot tertinggi (dalam penelitian ini adalah 5)

$\mathrm{N}$ = Jumlah total responden

Dalam penelitian ini, human error factor ditentukan dari 10 nilai variabel teratas berdasarkan peringkat relative importance index (RII). 


\section{ANALISIS}

\section{Uji Instrumen Data}

Berdasarkan uji validitas, reliabilitas, dan normalitas data yang telah dilakukan, maka diperoleh kesimpulan:

a. Keseluruhan item variabel memenuhi persyaratan validitas data.

b. Keseluruhan item variabel memenuhi persyaratan reliabilitas data.

c. Data yang diperoleh merupakan data yang tidak terdistribusi normal, sehingga statistik yang dipakai adalah statistik non-parametric.

\section{Karakteristik Responden}

Karakteristik responden didapatkan dari hasil jawaban responden pada bagian informasi data responden dari jumlah keseluruhan responden (Owner, Konsultan Perencana, Konsultan Pengawas, Kontraktor). Karakteristik responden dikelompokkan atas jenis kelamin, kelompok usia, tingkat pendidikan, pelaku konstruksi, dan lama bekerja. Adapun data-datatersebut dijelaskan pada tabel 2 berikut:

Tabel 2. Persentase Karakteristik Responden

\begin{tabular}{|c|c|c|c|c|}
\hline No & \multicolumn{2}{|c|}{ Karakterisik Responden } & Frekuensi & Persentase (\%) \\
\hline \multirow{2}{*}{1.} & \multirow{2}{*}{ Jenis kelamin } & Pria & 60 & 100 \\
\hline & & Wanita & 0 & 0 \\
\hline \multirow{4}{*}{2.} & \multirow{4}{*}{ Usia } & $<20$ Tahun & 3 & 5 \\
\hline & & 20-30 Tahun & 17 & 28.33 \\
\hline & & 30-40 Tahun & 18 & 30 \\
\hline & & $>40$ Tahun & 22 & 36.67 \\
\hline \multirow{5}{*}{3.} & \multirow{5}{*}{ Pendidikan } & SD & 0 & 0 \\
\hline & & SMP & 0 & 0 \\
\hline & & SMA & 26 & 43.33 \\
\hline & & S1 & 19 & 31.67 \\
\hline & & S2 & 15 & 25 \\
\hline \multirow{4}{*}{4.} & \multirow{4}{*}{ Pelaku Konstruksi } & Owner & 15 & 25 \\
\hline & & Konsultan Perencana & 15 & 25 \\
\hline & & Kontraktor & 15 & 25 \\
\hline & & Konsultan Pengawas & 15 & 25 \\
\hline \multirow{3}{*}{5.} & \multirow{3}{*}{ Lama Bekerja } & $1-3$ tahun & 9 & 15 \\
\hline & & $3-5$ tahun & 21 & 35 \\
\hline & & Lebih dari 5 tahun & 28 & 46.67 \\
\hline
\end{tabular}

\section{Relative Importance Index (RII)}

Berdasarkan analisis relative importance index (RII), didapatkan didapatkan faktor-faktor yang menjadi human error factor melalui 10 peringkat teratas relative importance index (RII), sehingga didapatkan 10 faktor utama human error pada proyek pada pembangunan jembatan Paya Dapur - Kp. Tinggi di Kabupaten Aceh Selatan pada tabel 3 di bawah ini:

Tabel 3. Faktor Utama Human Error Proyek

\begin{tabular}{cclc}
\hline No. & Variabel & \multicolumn{1}{c}{ Faktor } & Nilai RII \\
\hline 1. & X28 & Peran dan tanggung jawab konsultan pengawas dan konsultan perencana belum maksimal & 40.667 \\
\hline 2. & X26 & Kegagalan menggunakan alat pelindung diri/keselamatan diri dengan benar & 40.667 \\
\hline 3. & X7 & Prosedur kerja yang buruk & 40.333 \\
\hline 4. & X8 & Standard Operation Procedure (SOP) yang buruk & 40.000 \\
\hline 5. & X22 & Pencahayaan kurang baik & 40.000 \\
\hline 6. & X11 & Standar kerja sering digampangkan & 39.667 \\
\hline 7. & X10 & Tidak melakukan pemeriksaan awal & 39.667 \\
\hline 8. & X17 & Desain peralatan yang tidak sesuai atau tidak cocok dengan pengguna & 39.667 \\
\hline 9. & X23 & Tingkat kebisingan yang berlebihan & 39.333 \\
\hline 10. & X24 & Rancangan tata letak fasilitas kerja yang buruk & 39.000 \\
\hline
\end{tabular}


Berdasarkan perhitungan relative importance index (RII) juga didapatkan faktor-faktor yang mempengaruhi human error melalui 5 peringkat teratas untuk setiap kategori faktor yang ditunjukkan pada tabel 4 di bawah ini:

Tabel 4. Human Error Untuk Setiap Kategori Variabel

\begin{tabular}{|c|c|c|c|c|}
\hline No. & Kategori & Variabel & Faktor & Nilai RII \\
\hline \multirow[t]{5}{*}{1.} & Induced Human & $\mathrm{X} 7$ & Prosedur kerja yang buruk & 40.333 \\
\hline & Error System & $\mathrm{X} 8$ & Standard Operating Procedure (SOP) yang buruk & 40.000 \\
\hline & & $\mathrm{X} 11$ & Standar kerja yang digampangkan & 39.667 \\
\hline & & $\mathrm{X} 10$ & Tidak melakukan pemeriksaan awal & 39.667 \\
\hline & & $\mathrm{X} 5$ & Situasi yang benar-benar tidak diketahui & 39.000 \\
\hline \multirow[t]{5}{*}{2.} & $\begin{array}{l}\text { Induced Human } \\
\text { Error Design }\end{array}$ & $\mathrm{X} 28$ & $\begin{array}{l}\text { Peran dan tanggung jawab konsultan pengawas dan konsultan perencana belum } \\
\text { maksimal }\end{array}$ & 40.667 \\
\hline & & $\mathrm{X} 26$ & Kegagalan menggunakan alat pelindung diri/keselamatan diri dengan benar & 40.667 \\
\hline & & $\mathrm{X} 22$ & Pencahayaan kurang baik & 40.000 \\
\hline & & $\mathrm{X} 17$ & Desain peralatan yang tidak sesuai atau tidak cocok dengan pengguna & 39.667 \\
\hline & & $\mathrm{X} 23$ & Tingkat kebisingan berlebihan & 39.333 \\
\hline \multirow[t]{5}{*}{3.} & Pure Human & $\mathrm{X} 48$ & Tidak punya pengalaman ketika bekerja & 37.333 \\
\hline & Error & $\mathrm{X} 45$ & Pekerja menderita sakit atau masalah medis lainnya & 37.000 \\
\hline & & $\mathrm{X} 40$ & Kurangnya imajinasi/ tinjauan kedepan & 36.667 \\
\hline & & $\mathrm{X} 47$ & Tidak fokus pada pekerjaan & 36.333 \\
\hline & & $\mathrm{X} 44$ & Pekerja mengalami stress, mempunyai masalah pribadi & 36.000 \\
\hline
\end{tabular}

\section{PENUTUP}

\section{Kesimpulan}

Berdasarkan hasil analisis data yang telah dilakukan, maka terdapat 3 kategori human error factor dalam pembangunan infrastruktur jembatan Paya Dapur - Kp. Tinggi di Provinsi Aceh Selatan yaitu Induced Human Error System, Induced Human Error Design dan Pure Human Error.

Berdasarkan hasil penelitian dan pembahasan yang dilakukan, maka didapatkan 5 peringkat teratas human error factor pada masing-masing kategori, yaitu:

a. Induced Human Error System, faktor-faktor yang mempengaruhi adalah:

- Prosedur kerja yang buruk,

- Standard operating procedure (SOP) yang buruk,

- Standar kerja yang diremehkan,

- Situasi yang benar-benar tidak diketahui

- Tidak melakukan pemeriksaan awal

b. Induced Human Error Design. faktor-faktor yang mempengaruhi adalah:

- Peran dan tanggung jawab konsultan pengawas dan konsultan perencana belum maksimal

- Kegagalan menggunakan alat pelindung diri/keselamatan diri dengan benar

- Pencahayaan kurang baik

- Desain peralatan yang tidak sesuai atau tidak cocok dengan pengguna

- Tingkat kebisingan berlebihan.

c. Pure Human Error, faktor-faktor yang mempengaruhi adalah:

- tidak punya pengalaman ketika bekerja

- pekerja menderita sakit atau masalah medis lainnya

- kurangnya imajinasi/ tinjauan ke depan

- tidak fokus pada pekerjaan

- pekerja mengalami stress atau mempunyai masalah pribadi 


\section{Saran}

Berdasarkan hasil penelitian dan kesimpulan diatas, maka diajukan beberapa saran sebagai berikut:

a. Penelitian ini diharapkan dapat memberikan kontribusi kepada berbagai pihak yang terkait dalam program-program pembangunan infrastruktur, baik pemerintah, swasta, masyarakat, serta stakeholder lainnya, untuk lebih memahami dan mempertimbangkan faktor-faktor human error factor dalam proyek pembangunan infrastruktur.

b. Perlu dilakukan penelitian lebih lanjut dengan mempertimbangkan faktor manajemen keselamatan dan kesehatan kerja, sehingga terjadi kesinambungan antara sebab dan akibat dari suatu kejadian kecelakaan konstruksi

c. Penelitian ini diharapkan dapat dijadikan acuan dan bahan evaluasi penelitian selanjutnya untuk proyek pembangunan infrastruktur yang berbeda, serta lingkup penelitian dapat diperluas pada wilayah lainnya.

d. Data-data penelitian perlu ditambah dan dikumpulkan pada tahun terbaru, serta dengan metode dan pengolahan data yang berbeda untuk mendapatkan perbandingan hasil penelitian yang lebih akurat.

\section{DAFTAR PUSTAKA}

Atkinson, A.A.(1998), Advance Management Resource: Third Edition, Prentice-Hall, Inc, New Jersey

Arikunto, S. (2006), Prosedur Penelitian Suatu Pendekatan Praktik, Rineka Cipta, Jakarta.

Duffield, C., \& Trigunarsyah, B. (1999). Project Management - Conception to Completion.: Engineering Education Australia(EEA), Australia

Dhillon, Balbir S. 1987. Human Reliability: with Human Factors: Pergamon Press. United Kingdom

Effendi, M.T. (2007), Manajemen Sumber Daya Manusia: Pengadaan, Pengembangan, Pengkompensasian, dan Peningkatan Produktivitas Pegawai, Grasindo, Jakarta.

Ervianto, W.I (2005), Manajemen Proyek Konstruksi, Andi, Yogyakarta

Eldukair, Z.A, Ayyub, B.M (1991), Analysis of Recent US Structural and Constructional Failures, Journal of Performance of Construction Facilities Vol.5

Love, P. E. D. and Josephson, P. E., (2004), "Role of Error-Recovery Process in Project", J. of Management in Engineering, 20(2), 70-79. Canada.

Narbuko, C. \&Achmadi, A. (2001), Metode Penelitian, Bumi Aksara, Jakarta.

Reason, James, 1990 Human Error, Cambridge University Press, United Kingdom

Siti, S.S. (1999), Pengelolaan Tenaga Kerja Lepas Pada Kontraktor Indonesia Sebagai Bagian dari Sistem Manajemen Mutu, Tesis Magister ITB, Bandung.

Umar, H. (2004), Metode Riset Ilmu Administrasi, Gramedia Pustaka, Jakarta. 
INDENTIFIKASI FAKTOR RISIKO HUMAN ERRORS DALAM

Muhammad Khilbran, et.al

PENERAPAN MANAJEMEN SUMBER DAYA MANUSIA DI

PERUSAHAAN JASA KONSTRUKSI 